\title{
Erratum to: Two novel disaccharides, rutinose and methylrutinose, are involved in carbon metabolism in Datisca glomerata
}

\author{
Maria Schubert • Anna N. Melnikova • Nikola Mesecke • Elena K. Zubkova $\cdot$ Rocco Fortte \\ Denis R. Batashev $\cdot$ Inga Barth $\cdot$ Norbert Sauer $\cdot$ Yuri V. Gamalei - Natalia S. Mamushina • \\ Lutz F. Tietze $\cdot$ Olga V. Voitsekhovskaja $\cdot$ Katharina Pawlowski
}

Published online: 19 December 2009

(C) Springer-Verlag 2009

\section{Erratum to: Planta}

\section{DOI 10.1007/s00425-009-1049-5}

Unfortunately, the authors' contribution was missing and the Fig. 2 legend was wrong in the previous version.

The original version of authors' contribution and the Fig. 2 caption are given below.

Authors' contribution: O. V. Voitsekhovskaja and K. Pawlowski contributed equally to this manuscript.

The online version of the original article can be found under doi:10.1007/s00425-009-1049-5.

M. Schubert · N. Mesecke · O. V. Voitsekhovskaja · K. Pawlowski

Albrecht von Haller Institute for Plant Sciences,

Plant Biochemistry, Göttingen University,

37077 Göttingen, Germany

A. N. Melnikova · E. K. Zubkova · D. R. Batashev ·

Y. V. Gamalei · N. S. Mamushina · O. V. Voitsekhovskaja Komarov Botanical Institute, Russian Academy of Sciences,

197376 St. Petersburg, Russia

R. Fortte - L. F. Tietze

Institute of Organic and Biomolecular Chemistry,

Göttingen University, 37077 Göttingen, Germany

I. Barth · N. Sauer

Department of Molecular Plant Physiology,

University of Erlangen-Nürnberg, 90158 Erlangen, Germany

K. Pawlowski $(\bowtie)$

Department of Botany, Stockholm University,

10691 Stockholm, Sweden

e-mail: pawlowski@botan.su.se
Figure 2 legend:

Fig. 2 Time course of sugar contents ( $\mu \mathrm{mol} / \mathrm{g}$ fresh weight) in leaves (upper panel) and roots (lower panel) of D. glomerata. Plants were grown in aerated hydroponic culture at $16 \mathrm{~h}$ light, $8 \mathrm{~h}$ dark or $14 \mathrm{~h}$ light, $10 \mathrm{~h}$ dark, respectively, and samples (in duplicate) were taken for determination of sugar content in the middle of the light phase, $30 \mathrm{~min}$ before the end of the light phase, in the middle of the dark phase and $30 \mathrm{~min}$ before the end of the dark phase. The plants grown at $16 \mathrm{~h}$ light received $5 \mathrm{mM}$ $\mathrm{KNO}_{3}$ each week. The $\mathrm{KNO}_{3}$ in the growth medium of the plants grown at $14 \mathrm{~h}$ light had not been replenished since 3 weeks at the harvesting date 